The real cost of credit constraints: Evidence from micro-finance

Renuka Sane, Susan Thomas

Indira Gandhi Institute of Development Research, Mumbai July 2013

http://www.igidr.ac.in/pdf/publication/WP-2013-013.pdf 


\title{
The real cost of credit constraints: Evidence from micro-finance
}

\author{
Renuka Sane, Susan Thomas \\ Indira Gandhi Institute of Development Research (IGIDR) \\ General Arun Kumar Vaidya Marg \\ Goregaon (E), Mumbai- 400065, INDIA \\ Email (corresponding author): 는.in
}

\begin{abstract}
In December 2010, the Indian state of Andhra Pradesh passed a law that severely restricted the operations of micro-finance institutions and brought the micro-finance industry to an abrupt halt. We measure the impact of micro-credit withdrawal in this unique natural experiment and find that average household expenditure dropped by 19 percent relative to a control group after the ban. The largest decrease was observed in expenditure on food. There is some evidence of higher volatility in consumption after the ban. All households were affected and not just the borrower households, which may suggest general equilibrium effects.
\end{abstract}

Keywords: consumption smoothing, credit, household finance, micro-finance ban, natural experiment

JEL Code: D14, G21, G28

\section{Acknowledgements:}

We thank Ajay Shah for useful inputs into the research design. We also thank the articipants at the IGIDR seminar series, the ISI Delhi seminar series and the Emerging Markets Finance 2012 conference for helpful suggestions. The views expressed in this paper belong to the authors and not their employer. 


\title{
The real cost of credit constraints: Evidence from micro-finance
}

\author{
Renuka Sane \\ Susan Thomas* \\ Indira Gandhi Institute of Development Research
}

July 2013

\begin{abstract}
In December 2010, the Indian state of Andhra Pradesh passed a law that severely restricted the operations of micro-finance institutions and brought the micro-finance industry to an abrupt halt. We measure the impact of micro-credit withdrawal in this unique natural experiment and find that average household expenditure dropped by 19 percent relative to a control group after the ban. The largest decrease was observed in expenditure on food. There is some evidence of higher volatility in consumption after the ban. All households were affected and not just the borrower households, which may suggest general equilibrium effects.
\end{abstract}

JEL classification: D14, G21, G28

Keywords: consumption smoothing, credit, household finance, micro-finance ban, natural experiment

*Email: renuka@saner.org.in, susant@igidr.ac.in, URL: http://www.ifrogs. org We thank Ajay Shah for useful inputs into the research design. We also thank the participants at the IGIDR seminar series, the ISI Delhi seminar series and the Emerging Markets Finance 2012 conference for helpful suggestions. The views expressed in this paper belong to the authors and not their employer. 


\section{Contents}

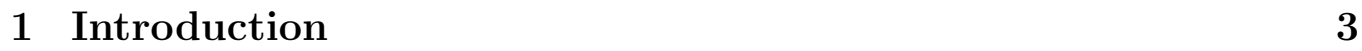

\begin{tabular}{|lll}
2 & The research setting & 5
\end{tabular}

2.1 A natural experiment: the micro-finance ban in Andhra Pradesh 7

$\begin{array}{llr}3 & \text { Questions } & 8\end{array}$

3.1 Did consumption fall when access to micro-finance was reduced? 8

3.2 Did volatility of consumption rise when access to micro-finance was reduced? . . . . . . . . . . . . . . . 9

3.3 Which households were more affected? . . . . . . . . . . . . . 9

\begin{tabular}{|lll}
4 & Household data for a matched analysis & 10
\end{tabular}

4.1 Income categories . . . . . . . . . . . . . . . . . . 11

4.2 Consumption . . . . . . . . . . . . . . . . . . . . 11

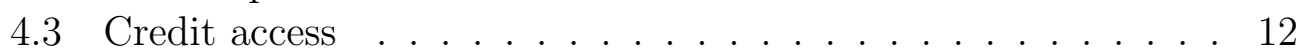

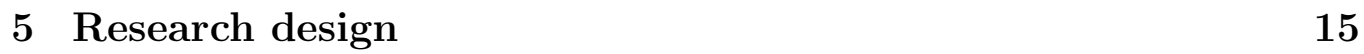

5.1 Matching procedure . . . . . . . . . . . . . . . 15

5.2 The difference-in-difference (DID) estimator . . . . . . . . . . 16

$5.3 \quad$ Evaluating the design $\ldots \ldots \ldots \ldots \ldots . \ldots \ldots$

5.3 .1 Is there match balance? . . . . . . . . . . . . . . 17

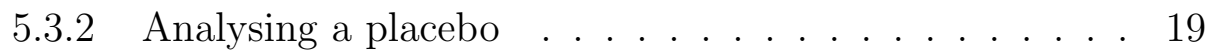

5.3.3 What is the size of the impact that can be resolved by the design? . . . . . . . . . . . . . . 19

$\begin{array}{llr}6 & \text { Results } & 23\end{array}$

6.1 Did consumption fall when access to micro-credit was reduced? 24

6.2 Did volatility of consumption rise with lower access to microfinance? . . . . . . . . . . . . . 27

6.3 Which households were more affected? . . . . . . . . . . . . . 28

\begin{tabular}{|lll}
\hline 7 & Threats to validity & 31
\end{tabular}

7.1 Did events other than the ban cause the results? . . . . . . . . 31

7.2 Are the results sensitive to the matching strategy?. . . . . . . 33

7.3 Is the match quality poor because South India is excluded? . . 33

8 Conclusion 35 


\section{Introduction}

New business models, in the last 20 years, have brought micro-credit to relatively poor households who have high income volatility, lack collateral and are denied credit by mainstream banking. These include 'pay-day loans' in developed economies and 'micro-finance' in emerging economies. For example, in 2009 about three to ten million American households were payday borrowers ${ }^{1}$, while there were reported to be 195 million micro-credit customers across the world in December 2011.2 Ordinarily, micro-credit would be considered unambiguously welfare improving, as it helps to ease liquidity constraints of households and enables better consumption smoothing. However, research shows that micro-credit customers are often not financially aware, overlook the costs of such borrowing, have time-inconsistent preferences and end up in financial distress (Thaler, 1990, Lusardi and Tufano, 2009 ; Skiba and Tobacman, 2009; Armendáriz and Morduch, 2010). These problems are exacerbated by alleged predatory lending practices and usurious interest rates charged by the for-profit lenders.

Policy makers in many countries have therefore asked questions about the extent to which micro-credit improves the lives of customers and, in some cases, have intervened to restrict such credit access. A small literature has developed in analysing the impact of events where payday lending in some states of the U.S. has been restricted. While Morgan and Strain (2008), Zinman (2010) and Morse (2011) find that household welfare was reduced when payday lending was restricted, Melzer (2011) shows that payday access worsens the debt burden of low-income households and does not improve their welfare. A drawback of most of these studies is that they do not observe household consumption directly, and utilise proxies of household credit health.

This paper analyses a policy intervention that forced a closure of the microfinance industry in the Indian state of Andhra Pradesh (AP). The intervention was motivated by a desire for customer protection, and led to an immediate reduction in access to borrowing for households in the state.

This was an ideal natural experiment in four respects. First, the ban was unexpected and complete. Second, it was an intervention on a large scale: in 2010, AP had a population of 84 million which exceeded that of Germany. Of these, an estimated 27 million were in households that borrowed from the

1 Skiba and Tobacman (2009)

2 http://stateofthecampaign.org/data/tables-and-figures/ 
micro-finance industry (Srinivasan, 2012). Third, high quality panel data about aggregated household consumption is available before and after the event. Fourth, controls are observed in the form of all the other states in India where there was no ban. This paper is, to our knowledge, the first rigorous analysis of this remarkable natural experiment.

The large scale withdrawal of credit, in a state the size of Germany, should have ramifications not only on individual households, who were customers of the micro-finance institutions, but also on the aggregate outcomes owing to general equilibrium effects. Borrower households are likely to save more to insure against future events. Some non-borrower households are also likely to save more in response to their expectation about a lack of access to credit when faced with shocks in the future. The reduced demand from both these groups could induce a demand shock which would have macroeconomic effects. In this, the episode being analysed is reminiscent of the economy-wide effects that have been seen in the macroeconomics and finance literature in episodes of deleveraging by a subset of the economy (Eggertsson and Krugman, 2012).

The dataset used in this paper is 'Consumer Pyramids', which releases average household characteristics of about 200 geographical units, named 'homogeneous regions' (HRs), across India. The underlying household survey that is used to obtain this information is a panel with 150,000 households every quarter. There are 800 observations of many sub-components of household consumption in each year. This is used to calculate the difference in the average household consumption expenditure for the regions where the micro-finance ban was implemented in the quarters before and after the ban. A counterfactual is constructed by identifying HRs which are similar to the treatment units but which did not suffer the ban. The causal effect of the ban is calculated as the difference-in-difference of the average household consumption between the treated HRs (in AP) and the controls (matched HRs outside AP).

The analysis finds that there was a significant decline in average household consumption in treatment HRs compared to control HRs. Consumption expenditure of households in the AP HRs decreased by 19.5 percent as a consequence of the ban on micro-finance. The magnitude of the decline varied across various sub-components of consumption. Households in AP spent 16 percent less on food and 34 percent less on education as a consequence of the ban on micro-finance. There is some evidence of higher volatility in the expenditure on food, which suggests greater difficulties by households in smoothing consumption as a consequence of the ban. Consumption across 
all income groups was negatively impacted by the micro-finance ban. The impact was however, bigger for households with liquidity constraints, such as those in rural regions with access to fewer sources of credit.

These results echo Morgan and Strain (2008) who find that the welfare of low-income households worsened in the states of Georgia and North Carolina, where payday lending was banned, and of Morse (2011) who point out that access to pay-day credit in the event of a natural disaster is welfare improving, even at interest rates of 400 percent.

This paper contributes to the literature on the role of credit, and particularly micro-credit, where there is considerable concern among policy makers worldwide about the extent to which unsophisticated borrowers make unwise decisions. The analysis of one extreme policy intervention, a ban, finds that it has fairly negative effects, not just for the poor but for the economy at large. More subtle interventions such as regulation with the objective of consumer protection may well be welfare-improving but a ban is not.

The paper is organised as follows. Economic questions about the effect of credit access on household consumption are discussed in Section2, and details of the event of the micro-finance ban implemented by the state government of Andhra Pradesh are discussed in Section 2.1. Section 3 presents the hypotheses tested. The data used for the analysis is described in Section 4 . The research design is presented in Section 5, which presents the matching methodology, and an evaluation of this methodology. Section 6 discusses the findings and Section 7 analyses the threats to the validity of these findings. Section 8 concludes.

\section{The research setting}

The bulk of the research about the effect of credit access on household consumption is based on randomised control trials (RCTs) ${ }^{3}$ This literature generally finds that, among other benefits, micro-credit helps households smooth consumption. There is similar evidence from general equilibrium models. Kaboski and Townsend (2011) find that access to micro-credit leads to higher levels of short-term borrowing, consumption and overall asset growth. Buera, Kaboski, and Shin (2012) find the benefits of access to micro-credit include higher wages and redistributive effects from high savers to low-savers. Both

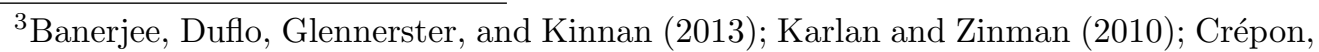
Devoto, Duflo, and Parienté (2011); Karlan and Zinman (2011); Augsburg et. al. (2012). 
approaches have their limitations. The external validity of the typical RCT is limited. Also, RCTs do not conduct studies where access to credit is withdrawn. General equilibrium models only analyse limited dimensions of how households use credit. For instance, Buera, Kaboski, and Shin (2012) do not measure the impact of consumption loans because such loans are not explicitly included in the model.

Natural experiments are another source of evidence where the trigger for the analysis is typically a policy intervention that changes the level of credit access for households. For example, Leth-Petersen (2010) analyses the impact on consumption loans in Denmark where there was a rule change that enabled higher credit against housing assets as collateral for consumption loans. They find an increase in consumption by younger (lower income) households. An advantage of studying such natural experiments is that the interventions can be an increase or a decrease in credit access. In the case of microcredit, where there have been rising concerns that access to expensive credit worsens household welfare, policy interventions have typically led to lower credit access.

For example, both Morgan and Strain (2008) and Zinman (2010) analyse policy changes where payday lending was restricted in different states in the U.S., in response to such concerns. Morgan and Strain (2008) find a decrease in household welfare when the states of Georgia and North Carolina banned payday credit. Zinman (2010) find that restricting access worsened the overall financial condition of households in Oregon. Morse (2011) uses natural disasters as the natural experiments and finds that access to payday loans allows households to cope through natural disasters and mitigate some forms of financial distress. In contrast Melzer (2011) finds no evidence that access to payday lending alleviates hardship, and instead reports that the associated debt service burden reduces the ability of low-income households to pay important bills. As a consequence, the evidence from these studies about the effect of credit access to household welfare is mixed.

A shortcoming of these papers which study natural experiments lies in measurement. While it is relatively easy to capture household consumption behaviour once an event has taken place, it is not possible to measure this before the event. Thus, most of this literature relies on proxies of household welfare. Morgan and Strain (2008) study the patterns in bounced cheques, complaints against debtors and bankruptcy filings, Zinman (2010) uses employment status and Morse (2011) analyses foreclosures on mortgages and small property crimes as proxies for household welfare. In this paper, we analyse a natural experiment of the largest ever ban in the world, and we 
are fortunate to observe household consumption expenditure before and after the intervention.

\subsection{A natural experiment: the micro-finance ban in Andhra Pradesh}

Micro-finance in India is largely a micro-credit industry. The loans offered by this industry have the same distinct features as micro-credit products elsewhere in the world: the loans are backed by social collateral; the borrowers are groups of women, typically between 4 and 20 in size; the loan amount is small $4^{4}$ and typically repaid within a year. There are a variety of micro-credit lenders in the Indian industry, from traditional money lenders to the self help group programs at banks and both non-profit and for-profit micro-finance institutions (MFIs). In the decade after 2000, the bulk of the growth in this field was in the for-profit MFI, and led to MFIs being regarded as an important channel of financial inclusion.

The state of Andhra Pradesh (AP) was the locus of growth of the microfinance industry in India. It was at the forefront of promoting the Self-Help Group (SHG) programs at banks, and was also the state where the largest MFIs were head-quartered. AP also had the largest share of micro-credit borrowers and loans outstanding in the country. However, there were many instances when these MFIs were accused of mis-selling and coercive collection practices $5^{5}$

On October $15^{\text {th }} 2010$, the state government proposed an ordinance that imposed operational constraints on the MFIs, ${ }^{6}$ which severely restricted the collection of loan repayments from customers, or the origination of new loans. This was enacted as law in December 2010. As a consequence, disbursements in the second half of the year were a mere 1.7 percent of loans disbursed in the first half. As well, more than Rs.7000 crore worth of loans in AP were effectively in default. The recovery out of these loans stood at about 10 percent (Srinivasan, 2012). While micro-finance came to a standstill in AP assets of the MFIs outside AP rose by 25 percent (MFIN, 2012).

\footnotetext{
${ }^{4}$ The size of the micro-loans in India are between USD 180 and USD 455 with a weekly repayment schedule.

${ }^{5}$ There are several sources detailing the role played by AP in the growth of the microfinance industry in India, and the subsequent problems that bedeviled the industry in this state. These include Datta and Mahajan (2003), Srinivasan (2010), Shylendra (2006), Sa-dhan (2007), Arunachalam (2010), Sane and Thomas (2013).

"State government of Andhra Pradesh (2010)
} 
The AP state government is said to have enabled the disbursal of loans through the SHGs. Provisional data however, indicates that the number of self-help groups availing loans during the year actually declined by 0.18 million and disbursements also declined by Rs.3.5 billion compared to the previous year. One estimate claims that a shortfall of about Rs.30 billion to households was not bridged (Srinivasan, 2012).

\section{Questions}

In the context of this natural experiment, we seek to answer the following questions about how micro-credit withdrawal affects consumption:

1. Is average household consumption affected when access to micro-finance is reduced?

2. Does the volatility of average consumption change?

3. Which households are more affected?

\subsection{Did consumption fall when access to micro-finance was reduced?}

Both Morgan and Strain (2008) and Zinman (2010) show a drop in household welfare when payday lending is restricted by analysing various economic indicators such as the ability of households to make payments or the employment status of the households.

We analyse the impact of the micro-finance ban by comparing the change in the average consumption of households in the HRs in AP to that of households in matched HRs outside AP. The first hypothesis that we test is:

$$
\begin{array}{ll}
H_{0}^{1}: & \Delta C_{\text {treatment }}=\Delta C_{\text {control }} \\
H_{A}^{1}: & \Delta C_{\text {treatment }}<\Delta C_{\text {control }}
\end{array}
$$

where we denote the difference in the consumption between the pre-ban and the post-ban periods as $\Delta C_{t}=C_{\text {post-ban }}-C_{\text {pre-ban }}$. 


\subsection{Did volatility of consumption rise when access to micro-finance was reduced?}

If access to credit helps to smooth consumption, then the withdrawal of access to micro-credit would imply that the household would be less able to maintain a constant level of consumption expenditure and the volatility of this consumption would increase.

We compare the variation in average consumption in the period after the ban with the period before the ban for households in the HRs in AP to that of households in matched HRs outside AP. The second hypothesis that we test is:

$$
\begin{array}{ll}
H_{0}^{1}: & {\left[\frac{\sigma^{2}\left(\Delta C_{\text {treatment,post-ban }}\right)}{\sigma^{2}\left(\Delta C_{\text {treatment,pre-ban }}\right)}\right]=\left[\frac{\sigma^{2}\left(\Delta C_{\text {control,post-ban }}\right)}{\sigma^{2}\left(\Delta C_{\text {control,pre-ban }}\right)}\right]} \\
H_{A}^{1}: & {\left[\frac{\sigma^{2}\left(\Delta C_{\text {treatment,post-ban }}\right)}{\sigma^{2}\left(\Delta C_{\text {treatment,pre-ban }}\right)}\right]>\left[\frac{\sigma^{2}\left(\Delta C_{\text {control,post-ban }}\right)}{\sigma^{2}\left(\Delta C_{\text {control,pre-ban }}\right)}\right]}
\end{array}
$$

where we denote the percentage change in consumption between consecutive periods, $t, t-1$, as $\Delta C_{t}=\log \left(C_{t} / C_{t-1}\right)$.

\subsection{Which households were more affected?}

Kaboski and Townsend (2012) suggest that households with short-term liquidity constraints will be more vulnerable to changes in credit access. We test changes in the average consumption of different categories of households as follows: Is the consumption of households with higher liquidity constraints more affected?

$$
\begin{array}{ll}
H_{0}^{2}: & \Delta C_{\text {high liquidity constraints }}^{D}=\Delta C_{\text {low liquidity constraints }}^{D} \\
H_{A}^{2}: & \Delta C_{\text {high liquidity constraints }}^{D}>\Delta C_{\text {low liquidity constraints }}^{D}
\end{array}
$$

where $\Delta C_{i}=\Delta C_{\text {pre-ban }}-\Delta C_{\text {post-ban }}$ measured for the set of households with $i=$ low liquidity constraints, high liquidity constraints, and $\Delta C^{D}=\Delta C_{\text {treatment }}-$ $\Delta C_{\text {control }}$. 


\section{Household data for a matched analysis}

The "Consumer Pyramids" (CP) database 7 is based on a national panel survey covering 150,000 households. The survey has been administered every quarter from June 2009 onwards.

The data that is released consists of averages rather than individual household observations. These averages are calculated for the households within a defined geographical region called a Homogenous Region or HR. Each HR is a group of two or more districts within a state. There are $14 \mathrm{HRs}$ in AP and a total of $200 \mathrm{HRs}$ in India. Among the HRs in AP, there are seven in a rural region and seven in an urban region, which provides useful variation in levels of credit constraints. The $14 \mathrm{HRs}$ in AP contain 10,951 out of the 150,000 households sampled all over India.

Since the survey is implemented on a national scale, it allows us to also observe household behaviour in states which did not ban micro-finance as AP did. This facilitates the creation of a counterfactual for the effect of the ban on households in AP if we can observe the behaviour of households in regions whose social and economic characteristics match the AP regions, but that did not suffer the ban. A comparison of the treatment HRs (those in AP) and the control HRs (the matched regions) yields causal inference about the impact of credit constraints.

The database contains two sets of aggregate information that are useful in the analysis on how different households respond to a ban on micro-finance:

1. Aggregate household income and consumption expenditure, as well as the number of households used, which are reported each quarter.

Consumption expenditure is further broken down by categories such as food, fuel, education, etc. This breakup can be useful to analyse any variation in the effect of the ban on different categories of consumption components.

2. Financial participation such as borrowings of households is reported as fraction of households in the region that borrow and borrow from specific sources such as friends and family, money-lender, bank and micro-finance (MFI/SHG), categorisation of HRs into rural and urban HRs. These can be used to identify which households are likely to have higher and lower liquidity constraints.

${ }^{7}$ The CP database is created by the Centre for Monitoring Indian Economy (CMIE). http://www. consumer-pyramids. com 
Table 1 Household types by income categories for the full sample

The survey captures monthly income of all members of the household for the six-month period ending the reference month of the survey. This is annualised and aggregated to derive the annual income of the household.

Income groups are formed at various percentiles. The corresponding income values by groups are rounded to the nearest thousand rupees to reflect how respondents report their incomes.

\begin{tabular}{rrrr}
\hline & & \multicolumn{2}{c}{ (in September 2010) } \\
\hline & Annual household income (Rs.) & \% share in \\
Lower limit & Upper limit & total sample \\
\hline I-1 & $1,000,000$ & Infinity & 1.0 \\
I-2 & 720,000 & $1,000,000$ & 1.4 \\
I-3 & 360,000 & 720,000 & 8.8 \\
I-4 & 240,000 & 360,000 & 11.7 \\
I-5 & 180,000 & 240,000 & 10.9 \\
I-6 & 120,000 & 180,000 & 16.6 \\
I-7 & 96,000 & 120,000 & 9.9 \\
I-8 & 60,000 & 96,000 & 19.3 \\
I-9 & 36,000 & 60,000 & 15.2 \\
I-10 & 24,000 & 36,000 & 3.5 \\
I-11 & 0 & 24,000 & 1.7
\end{tabular}

We now describe the average household income, consumption and financial participation, for India and for AP.

\subsection{Income categories}

Table 1 reports the various income categories reported in the CP database and the fraction of the households that fall into these income categories. For instance, the largest fraction of households fall in the "I-8" category (nearly 20 percent), where the annual income of the household is between Rs.60,000 (USD 1111) and Rs.96,000 (USD 1778).

\subsection{Consumption}

Table 2 reports what the household consumes. The largest component is food, which is almost 50 percent of the household expenses. This is followed by fuel at 10 percent. This allows us to test how households change consumption in 


\section{Table 2 Components of consumption}

The table presents components of household consumption reported in the CP database and the percentage share of each for AP households in September 2010, which is two quarters before the ban.

\begin{tabular}{llr}
\hline $\begin{array}{l}\text { Consumption } \\
\text { On }\end{array}$ & Description & $\begin{array}{r}\text { \% share in } \\
\text { Total }\end{array}$ \\
\hline Food & & 48.7 \\
Power and Fuel & Cooking fuel, petrol, diesel, electricity & 9.6 \\
Cosmetics & Includes toiletries & 7.1 \\
Education & Books and various fees & 5.5 \\
Miscellaneous & Includes tourism, social obligations & 4.8 \\
Communication & Telephone, newspaper, TV, internet & 4.6 \\
Clothing & Garments, footwear and accessories & 4.5 \\
Transport & Bus/train/autorickshaw & 3.8 \\
Intoxicants & Cigarettes and alcohol & 2.7 \\
Rent & House rent and other charges & 2.2 \\
Monthly repayments (EMIs) & Installments on cars, durable goods, home & 1.9 \\
Restaurants & & 1.8 \\
Health & Medicines, doctor fees, hospitalisations & 1.6 \\
Recreation & CDs, movies, toys & 1.0 \\
\hline
\end{tabular}

different components in response to worsening credit constraints. 8

\subsection{Credit access}

We observe household borrowing as a binary variable, of whether households borrowed from a particular source, for all sources of borrowing. While it would have been ideal to have the quantum of borrowings by the household, even the binary response reveals interesting patterns of household credit access, when this is used in conjunction with income categories.

Table 3 presents the proportion of households that have borrowings across different income categories from different sources of credit, both informal (friends and family, money lenders) and formal (banks and SHG/MFIs). Extrapolation from the $\mathrm{CP}$ database yields an estimate of 28 million customers of micro-credit (SHG + MFI), which tallies well with the 27 million estimated by (Srinivasan, 2012).

\footnotetext{
${ }^{8}$ Ballem et.al. (2011) reports that respondents claim to have scaled back their business plans, or cut down on expenditure on school fees and marriages after the micro-finance ban in AP.
} 


\section{Table 3 Who borrows and from where: All India and AP in 2010-11}

The table reports the fraction of households borrowing from various sources in the four quarters of fiscal year 2010-11, in India and in Andhra Pradesh (AP). The last column in the table shows the fraction of households in each income group in the region who have some borrowing. This varies from a fifth of the richest to a bit less than half of the poorest in India. This changes dramatically in the case of AP where more than half the sample borrows.

The table also shows the sources from which these households have borrowings. Of the five sources, the SHG/MFI are the micro-finance lenders.

The role of banks peaks for the households in the $\mathbf{I} 4$ category with mean annual income of Rs. 300,000 both in India and in AP. It steadily peters away when dealing with lower income categories, going down to less than 5 percent of the households for the poorest in India, and less than 10 percent of the poorest households in AP.

Micro-finance plays an important role for households with an average annual income of less than Rs.100,000, serving around 8 percent of the households in all India and around 40 percent of the households in AP.

\begin{tabular}{|c|c|c|c|c|c|c|c|}
\hline & \multirow[b]{2}{*}{ No. of $\mathrm{HH}$} & \multicolumn{6}{|c|}{ Sources of Borrowing } \\
\hline & & Friends & Money lenders & SHG/MFI & Banks & Others & Any \\
\hline \multicolumn{8}{|l|}{ India: } \\
\hline I1 (Rich) & 438 & 0.44 & 0.12 & 0.12 & 17.69 & 1.29 & 19.81 \\
\hline $\mathrm{I} 2$ & 887 & 2.92 & 2.86 & 0.28 & 15.29 & 3.24 & 19.14 \\
\hline I3 & 8222 & 7.88 & 6.56 & 0.70 & 18.77 & 6.85 & 27.08 \\
\hline I4 & 13200 & 9.87 & 7.71 & 1.65 & 19.17 & 7.30 & 31.53 \\
\hline I5 & 14314 & 11.60 & 7.83 & 2.09 & 14.59 & 7.23 & 32.42 \\
\hline I6 & 24434 & 16.24 & 10.23 & 4.05 & 13.09 & 8.69 & 36.52 \\
\hline I7 & 15189 & 20.60 & 13.01 & 6.12 & 10.41 & 10.66 & 41.97 \\
\hline I8 & 33389 & 21.65 & 14.47 & 6.99 & 7.31 & 11.28 & 40.27 \\
\hline I9 & 28796 & 24.69 & 14.26 & 7.64 & 5.20 & 11.67 & 42.55 \\
\hline I10 & 7786 & 29.46 & 14.06 & 7.06 & 4.60 & 10.11 & 46.07 \\
\hline I11 (Poor) & 2658 & 30.00 & 13.33 & 6.65 & 3.13 & 8.71 & 44.91 \\
\hline Total & 149313 & 20.42 & 12.45 & 5.76 & 9.18 & 10.10 & 36.69 \\
\hline \multicolumn{8}{|l|}{ AP: } \\
\hline I1 (Rich) & 2 & & & & & & \\
\hline I2 & 6 & & 67.76 & & & & 67.76 \\
\hline I3 & 131 & 33.90 & 23.57 & 3.80 & 25.61 & 8.83 & 47.06 \\
\hline I4 & 471 & 30.72 & 21.45 & 20.58 & 26.10 & 8.51 & 55.67 \\
\hline I5 & 775 & 44.56 & 30.07 & 16.26 & 20.16 & 13.33 & 63.05 \\
\hline I6 & 2014 & 52.25 & 41.23 & 26.65 & 20.84 & 16.48 & 74.14 \\
\hline I7 & 1531 & 61.14 & 50.84 & 32.65 & 16.92 & 22.57 & 82.56 \\
\hline I8 & 3598 & 58.67 & 54.40 & 35.51 & 14.47 & 25.82 & 85.43 \\
\hline I9 & 2179 & 62.00 & 54.91 & 39.04 & 12.56 & 31.54 & 86.69 \\
\hline I10 & 200 & 60.00 & 58.28 & 34.06 & 9.14 & 29.32 & 88.02 \\
\hline I11 (Poor) & 44 & 51.70 & 60.28 & 41.21 & 6.87 & 22.75 & 87.53 \\
\hline Total & 10951 & 57.46 & 50.31 & 33.37 & 15.64 & 24.49 & 82.67 \\
\hline
\end{tabular}


Table 4 Purpose of borrowing in AP, March 2010

This table presents the proportion of borrower households in AP that have borrowed for various purposes. For example, 69 percent of borrower households in the I-3 income category reported having borrowed for the purpose of housing. A household may borrow for more than one reason. Among the columns in the table, Number is the number of borrower households in each income category; Consumption includes reasons of general consumption, but excludes reasons of health, marriage and education; Investment includes borrowing for business purposes as well as investments in other instruments.

\begin{tabular}{lrrrrrr}
\hline & $\begin{array}{c}\text { Number of } \\
\text { households }\end{array}$ & Housing & Consumption & Durables & Investment & $\begin{array}{c}\text { Debt } \\
\text { repayment }\end{array}$ \\
\hline I-3 & 46 & 45.2 & 46.8 & 10.8 & 55.7 & 27.3 \\
I-4 & 192 & 29.8 & 51.7 & 7.6 & 53.1 & 22.0 \\
I-5 & 389 & 36.1 & 60.3 & 15.5 & 56.8 & 27.2 \\
I-6 & 1277 & 33.4 & 65.9 & 18.4 & 44.6 & 28.6 \\
I-7 & 1127 & 33.4 & 72.2 & 20.8 & 36.8 & 28.9 \\
I-8 & 2930 & 34.3 & 77.8 & 21.2 & 27.3 & 28.2 \\
I-9 & 1907 & 32.6 & 80.6 & 21.1 & 20.0 & 30.1 \\
I-10 & 175 & 28.7 & 77.9 & 13.2 & 21.4 & 27.5 \\
I-11 & 37 & 32.2 & 70.3 & 16.2 & 24.8 & 39.2 \\
\hline
\end{tabular}

Two observations in Table 3 merit mention. The first is that households across all income categories in India borrow from both formal and informal sources. What varies is the extent to which a given lender is the dominant source of credit for households in the various income categories. For instance, a higher fraction of high income households take loans from banks while the micro-finance channels (both SHG and MFI) are used by a larger fraction of lower income households. Secondly, we see that the incidence of borrowing in AP is higher than that seen in India.

We also examine the purpose for which households across various income groups in AP borrow in Table 4. This shows that consumption is the most important reason for which households take loans. Other than one income category (I-3), more than 50 percent of the households in other income categories borrow for consumption. A significant fraction of the higher income categories (I-3 to I-6) borrow to make investments and to purchase consumer durables. This is in contrast to the households in lower income categories, where a smaller fraction borrow for similar purposes. Thus, when a ban in micro-finance is implemented, it is likely to have a different impact on the higher and lower income households. 


\section{Research design}

We compare consumption in HRs in AP against similar HRs in India where there was no ban. This allows us to implement a DID estimation as follows: one set of observations are the households from AP (the treatment group). The counterfactuals consists of HRs that had no ban, which match the treatment units on some observables.

\subsection{Matching procedure}

The purpose of the matching exercise is to pair HRs based on some observable variables such that consumption in the treatment and control regions is comparable before and after the micro-finance ban. First, a set of observable characteristics are chosen based on which the matching should be done. Second, we establish a distance measure and choose the optimal matched HR for each treatment HRs.

Match variables We choose two broad categories of co-variates using which to match regions: those that measure the prosperity of the region, and those that measure the access to finance in the region. A match using such covariates would create a treatment and control that behave alike in consumption if the micro-finance ban is not implemented. Towards this objective, the following covariates are chosen:

1. The average income of households.

2. The number of households.

3. The working population, measured as the proportion of the HR that is in the working age. Here, working age is between 20 and 60 years.

4. The proportion of households who have graduated the $10^{\text {th }}$ grade.

5. The proportion of the population that is financially excluded. This is measured as the fraction of households in the HR that do not have a bank account, credit card, life insurance policy, or other similar formal financial products.

6. The proportion of farmers in the region? 9

\footnotetext{
${ }^{9}$ The household participation in the agricultural sector of a region has implications for fluctuations in income and therefore, the need to access finance for consumption smoothing (Rosenzweig, 2001).
} 
We do not use the presence of micro-finance institutions as a match variable because it is directly effected by the treatment. We also do not use the observed outcome variables in the matching procedure as it introduces certain difficulties in estimation (Stuart, 2010).

Distance measure of the match As the policy change was exogenous, we use the Mahalonobis distance measure for nearest neighbour matching, which is calculated as follows:

$$
D_{i j}=\left[\left(X_{i}-X_{j}\right)^{\prime} \Sigma^{-1}\left(X_{i}-X_{j}\right)\right]^{\frac{1}{2}}
$$

where $D_{i j}$ is the distance between unit $i$ and $j$ and $X_{i}$ and $X_{j}$ are the characteristics of the control and treatment units. A "1:1 nearest neighbor matching" method selects the control unit with the smallest distance from any given treated unit $i$.

Alternative approaches to matching are examined as part of the sensitivity analysis in Section 7.2 .

Neighbouring states in South India may have suffered from an indirect treatment effect, either because of transmission of shocks through trade, or because of political actions by state governments that are similar to those undertaken in AP. Hence, when constructing the control pool, we exclude the HRs in the states of South India - Tamil Nadu, Kerala and Karnataka which might have suffered from spillovers of the ban in AP. The sensitivity to this design decision is evaluated in Section 7.3

\subsection{The difference-in-difference (DID) estimator}

Since we observe consumption of the treatment and the control HRs, before and after the ban, we use a difference-in-difference (DID) estimator. The following DID model is estimated:

$$
C_{i, t}=\beta_{0}+\beta_{1} \mathrm{AP}_{i, t}+\beta_{2} \mathrm{POST}_{-\mathrm{CRISIS}_{i, t}}+\beta_{3}\left(\mathrm{AP}_{i, t} \times \operatorname{POST}_{-\mathrm{CRISIS}_{i, t}}\right)+\epsilon_{i, t}
$$

where $C_{i, t}$ is the average household consumption, AP is a dummy which takes value " 1 " if $i$ is a region in AP (the treatment HR) and " 0 " otherwise (the control HR), POST-CRISIS captures whether the observation is from the period before the micro-finance ban (post-crisis = "0") or after (post-crisis = "1"). The PRE-CRISIS quarters include the four quarters of March, June, September and December 2010. POST-CRISIS includes the four quarters of March, June, September and December 2011. If the average household consumption in the treatment HRs sees a greater fall compared to that in the 
matched HRs after the micro-finance ban, then $\hat{\beta}_{3}$ will be negative and statistically significant.

The matching DID estimator is a considerable improvement on standard matching estimators (Blundell and Dias, 2000), since it enables the elimination of unobserved time-invariant differences in expenditures between the treatment and control regions that standard matching estimators fail to eliminate (Smith and Todd, 2005). It is also an improvement on a simple DID where it is not clear that the treatment and control units are alike, and have match balance.

\subsection{Evaluating the design}

We now evaluate the design from three points of view. Is there match balance? How does the design fare when presented with a placebo (a non-event)? And how much power do we have?

\subsubsection{Is there match balance?}

In a sound design, match balance should be achieved between the treatment and control HRs. This implies that the distribution of the $X$ co-variates observed for the treatment and control HRs are equal in the pre-treatment period. When match balance is inadequate, the estimation of treatment effects relies on extrapolation, which is fraught with difficulties (Rosenbaum and Rubin, 1983).

Table 5 presents results from parametric tests, including a paired t-test and the standardised bias for the $X$ co-variates 10 The t-stats confirm that there is no significant difference between the two groups, for all the variables, including those for whom the standardised bias is above 20.11 The last column titled "\% Bal. Impr." is the percent improvement in balance for each of the

\footnotetext{
${ }^{10}$ The standardised bias for (say) the income variable is defined as the difference in means between the HRs in AP and the appropriately matched comparison group of the HRs outside of AP, scaled by the average variance of the income variables in the two groups.

${ }^{11} \mathrm{~A}$ lower standardised difference provides evidence that the treatment and control groups are balanced. While there is no formal criterion for appropriate value of standardised difference, a value of upto 20 is considered acceptable (Rosenbaum and Rubin, 1985). In our sample, the standardised difference is less than or close to 20, except for one covariate, the number of households.
} 
Table 5 Match balance using t-stat and standardised difference

This table presents the match balance statistics between the treatment and control group. The $\mathrm{p}$ values ( $\mathrm{p}$-val) are generated from the t-test, and SDIFF reflects the standardised difference.

$\%$ balance improvement refers to the improvement in balance after matching for all the covariates.

\begin{tabular}{|c|c|c|c|c|c|c|c|}
\hline & $\begin{array}{r}\text { Means } \\
\text { Treated }\end{array}$ & $\begin{array}{r}\text { Means } \\
\text { Control }\end{array}$ & $\begin{array}{r}\text { Mean } \\
\text { Diff }\end{array}$ & t-stat & p-val & SDIFF & $\begin{array}{l}\text { \% Bal. } \\
\text { Impr. }\end{array}$ \\
\hline Average HH income & 10.25 & 10.33 & -0.09 & -0.80 & 0.43 & -24.78 & 58.30 \\
\hline No.of $\mathrm{HH}$ & 7.08 & 6.71 & 0.37 & 1.58 & 0.13 & 40.66 & 52.99 \\
\hline Working & 3.65 & 3.47 & 0.17 & 0.29 & 0.77 & 7.16 & 49.08 \\
\hline Graduated $10^{\text {th }}$ grade & 2.59 & 2.51 & 0.08 & -0.52 & 0.60 & -12.21 & 84.65 \\
\hline Financial excluded & 4.35 & 4.27 & 0.08 & 1.24 & 0.23 & 28.49 & 91.71 \\
\hline Farmer & 0.36 & 0.24 & 0.12 & -0.84 & 0.41 & -19.69 & 80.01 \\
\hline
\end{tabular}

covariates ${ }^{12}$ and shows the balance has substantially improved for all the co-variates as a consequence of the matching procedure.

Figure 1 plots the change in the standardised bias for all covariates after matching. This shows that the standardised bias fell significantly after matching with values in the range from 0.5 to 0.15 , compared with values in the range from 1.0 to 0.15 .

Stuart (2010) points out that the parametric tests such as the t-test are often not accurate measures of balance as they compare only the averages, while the entire distribution matters in a matching exercise. One test for this is a visual inspection of the quantile-quantile (QQ) plots for each covariate pair used in the matching exercise. If there is match balance, the points would fall on the $45^{\circ}$ line. Figure 2 shows that this is not the case with the full dataset, but is substantially the case with the matched data.

A final test is the Hotelling's T-square test which considers the joint significance of the differences between the co-variates. In the sample, the $\chi$-statistic is 10.44 with a p-value of 0.12 and the F-statistic is 1.35 with a p-value of 0.27 . Both these indicate that the differences between the covariates are not jointly significant.

All four tests confirm that match balance has been achieved, and that we have a sound design.

\footnotetext{
${ }^{12}$ The improvement in balance is defined as $100((|a|-|b|) /|a|)$, where $a$ is the balance before the matching, and $b$ is the balance after matching.
} 
Figure 1 Difference in the standardised bias

The figure shows the change in standardised bias after matching. The left hand dots show the standardised bias for the entire data-set, while the right hand shows that for the matched data-set.

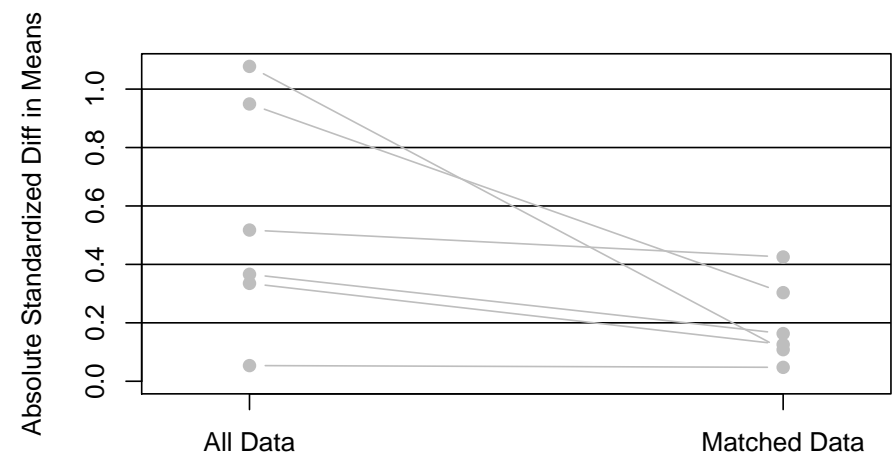

\subsubsection{Analysing a placebo}

In order to examine the soundness of the estimation strategy, we explore how it behaves in a simulation study. We conduct a Monte-Carlo simulation with a placebo, where $14 \mathrm{HRs}$ are selected at random which are considered the treated HRs. We exclude HRs in AP in this exercise. For the selected HRs, we carry out the matching exercise to find control HRs. We then test the difference between this treatment and control HRs using a DID estimation. This simulation is repeated 10,000 times.

Table 6 presents the results of the simulation exercise. While the rejection rate is not exactly the same as the size of the test, this serves as a check that when presented with a placebo, the estimation strategy does not reject the null incorrectly.

\subsubsection{What is the size of the impact that can be resolved by the design?}

One concern about our design lies in the fact that we only a small dataset of 14 HRs (while recognising that these 14 HRs represent aggregates of 10,591 underlying households). Our ability to reject the null when the null is not true may be limited owing to this small sample. Hence, we undertake a power 
Figure 2 QQ plots of the match covariates

The figure plots the QQ-plots of the covariates used in matching, before and after the matching exercise. The y-axis in each box reflects the treated units and the $\mathrm{x}$-axis the control units. Deviations from the $45^{\circ}$ line indicate differences in the empirical distribution and a low match balance. In all cases, there is good match balance after the matching is done.

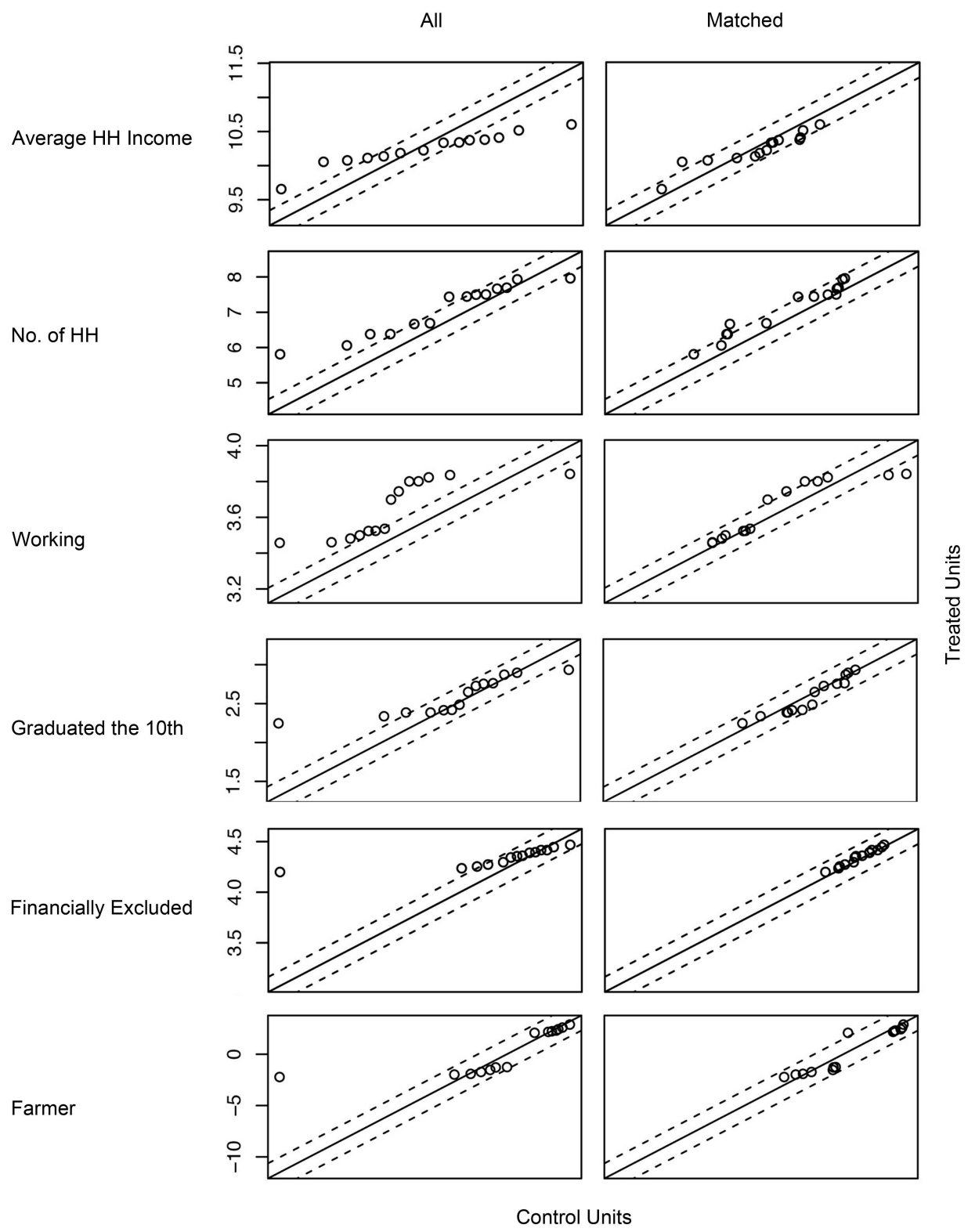




\section{Table 6 Analysing a placebo}

The table reports the results of a simulation with 10,000 runs. In each run, 14 randomly chosen HRs are taken as the treated unit, and the matching procedure is used to find controls. The DID model in Section 5.2 is then estimated, where the null of no effect is true. The table shows the probability of rejecting the null.

\begin{tabular}{lc} 
& $\begin{array}{c}\text { Null rejected } \\
(\%)\end{array}$ \\
\hline Total & 0.0 \\
Food & 0.0 \\
Fuel & 0.0 \\
Cosmetics & 0.0 \\
Education & 0.2 \\
Miscellaneous & 0.0 \\
Communication & 0.0 \\
Clothing & 0.1 \\
Transport & 1.1 \\
Intoxicants & 0.9 \\
Rent & 0.0 \\
EMIs & 0.2 \\
Restaurant & 0.9 \\
Health & 0.5 \\
Recreation & 0.1
\end{tabular}


Table 7 How much power does the design have?

This table presents results from a simulation exercise that captures $Q_{\text {power }}$ which is the effect size that can be detected with a probability of 70 percent.

For example, in the case of power and fuel, $Q_{\text {power }}=400$ implies that if the true effect size was a change in expenditure on power and fuel of Rs.400, then it would be detected correctly by a test of 95 percent significance, with a 70 percent probability.

\begin{tabular}{lr}
\hline & $\begin{array}{r}Q_{\text {power }} \\
(\text { Rs. })\end{array}$ \\
\hline Total & 6000 \\
Food & 2000 \\
Power and fuel & 1000 \\
Cosmetics & 300 \\
Education & 500 \\
Miscellaneous & 2000 \\
Communication & 500 \\
Clothing & 500 \\
Transport & 400 \\
Intoxicants & 200 \\
Rent & 300 \\
EMIs & 500 \\
Restaurants & 400 \\
Health & 200 \\
Recreation & 100 \\
\hline
\end{tabular}

study in order to assess the magnitude of deviations from the null that can be detected through our design and estimation strategy.

For this, we run simulations where 14 HRs are randomly chosen to be a treatment group, and a shock is artificially induced into this set. The matching DID estimator is then used to test whether there is a statistically significant difference (at a 95 percent level of significance) between the treatment and the control. We report the size of the shock that is discerned with a 70 percent probability in Table 7. As an example, this shows that a change in total expenditure of Rs.6000 per quarter is discerned by a 95 percent test with 70 percent probability.

This shows that in most cases, we have fairly high power. For example, if the impact on food expense is bigger than Rs.2000, we are likely to discern it. Conversely, if our analysis showed that the null (no effect) cannot be rejected, this would imply that the true effect size is smaller than Rs.2000. 
$\overline{\text { Figure } 3 \text { Average quarterly household consumption, March 2010-September }}$ 2011

The graph shows the average total household consumption in the treatment HRs (in AP) and control HRs (matched, outside AP) between the March 2010 to September 2011 quarters.

The vertical bar marks the quarter in which the state government passed the micro-finance ban in Dec 2010. While consumption in the controls grew steadily through this period, consumption in AP dropped sharply from Rs.17,530 to Rs.15,190.

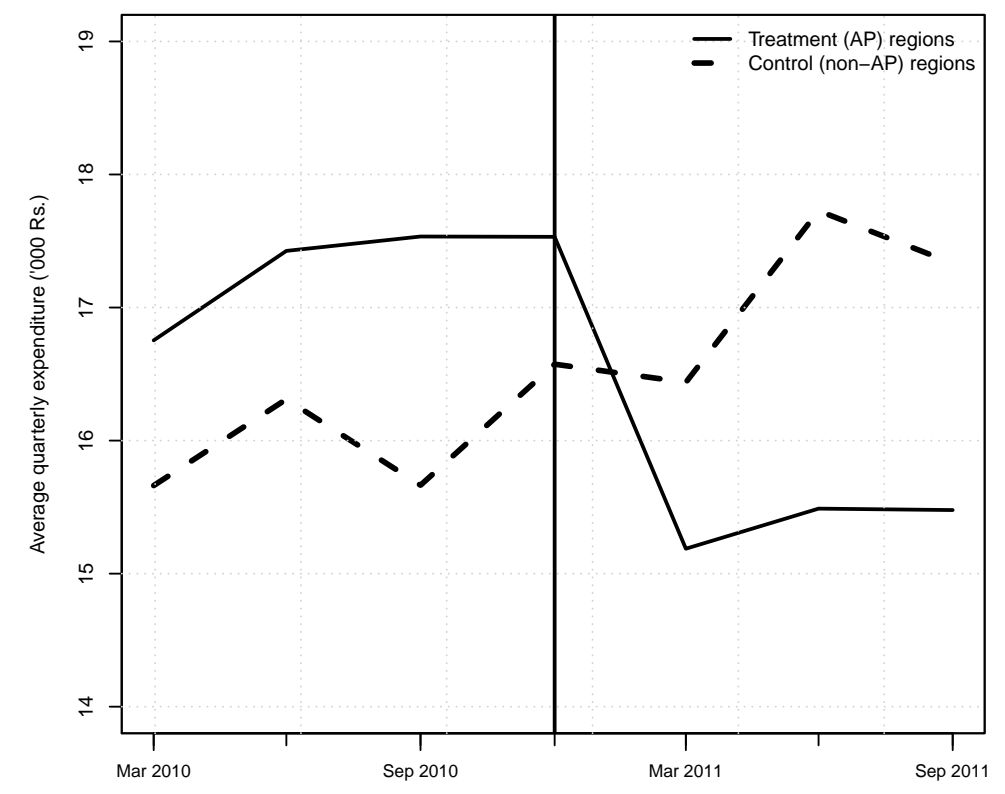

\section{Results}

The impact of the ban on micro-finance in AP is measured by the change in average household consumption in AP before and after the ban. Figure 3 plots the average household consumption in the 14 AP HRs as the solid line, in the graph from March 2010 upto September 2011. The average household consumption for the control HRs is plotted as the dashed line. We see a sharp drop in average consumption in the AP HRs after the micro-credit ban. 


\subsection{Did consumption fall when access to micro-credit was reduced?}

The first point of comparison is to analyse the impact of the ban one quarter before and one quarter after the micro-finance ban. The state government announced the ban in October 2010 and passed it as law in December 2010. This quarter is denoted as Mar 2011. The two points of comparison are the pre-ban quarter (denoted as the Dec 2010 quarter in Figure 3) and the post-ban quarter (denoted as the June 2011 quarter in Figure 3).

Average consumption in AP households dropped between the pre-ban and post-ban quarters. In contrast, average household consumption of the control HRs rose in the same period. The average AP household used to spend Rs.17,531 in a quarter on consumption in the pre-ban period. This dropped to Rs.15,487 in the post-ban period, a decrease of 12 percent over two quarters. In the control HRs households spent Rs.16,574 on average in the pre-ban period and Rs.17,727 in the post-ban period, a rise of seven percent. This suggests that the average quarterly household consumption in AP dropped by 19 percent as a consequence of the micro-finance ban.

Figure 4 plots the time series of the average household consumption in the treatment and control HRs for the top four consumption components listed in Table 2: food, power and fuel, cosmetics and toiletries and education. ${ }^{13}$ The average food expenditure in AP was Rs.8,480 in the pre-ban quarter which dropped to Rs.7,614 after the ban, an immediate decrease of 10 percent as a result of the ban. In contrast, households in the control HRs increased expenditure on food from Rs.8,256 to Rs.9,153 across these two quarters, which is an increase of 11 percent. Households in AP that spent Rs.500 in the pre-ban quarter on education expenditure spent Rs.668 $8^{14}$ after the ban. In contrast, households in the control HRs spent an average of Rs.529 in the pre-ban quarter and Rs.836 in the post-ban quarter. This implies that households in AP spent 24 percent less on education in the post-ban quarter because of the micro-finance ban.

We next analyse the impact of the ban using the estimates of $\beta_{3}$ of the DID models proposed in Section 5.2. From the $\hat{\beta}_{3}$ presented in Table 8 we see that the average household consumption expenditure over four quarters has fallen by an average of Rs.3,375 in the AP HRs relative to the control after the micro-finance ban. This drop is significant at the 5 percent level of

\footnotetext{
${ }^{13}$ Together, these account for 70 percent of household consumption in a quarter.

${ }^{14}$ These are small values. Rs.500 is around USD 9 and Rs.668 is USD 12.
} 
Figure 4 Variation in the top four household consumption components, before and after the ban

This figure reflects the average household expenditure for the treatment (AP) HRs and control HRs, for four components of consumption: food, power and fuel, cosmetics and toiletries and education for the quarters from March 2010 to September 2011.

The vertical bar indicates the quarter when the micro-finance ban was implemented.
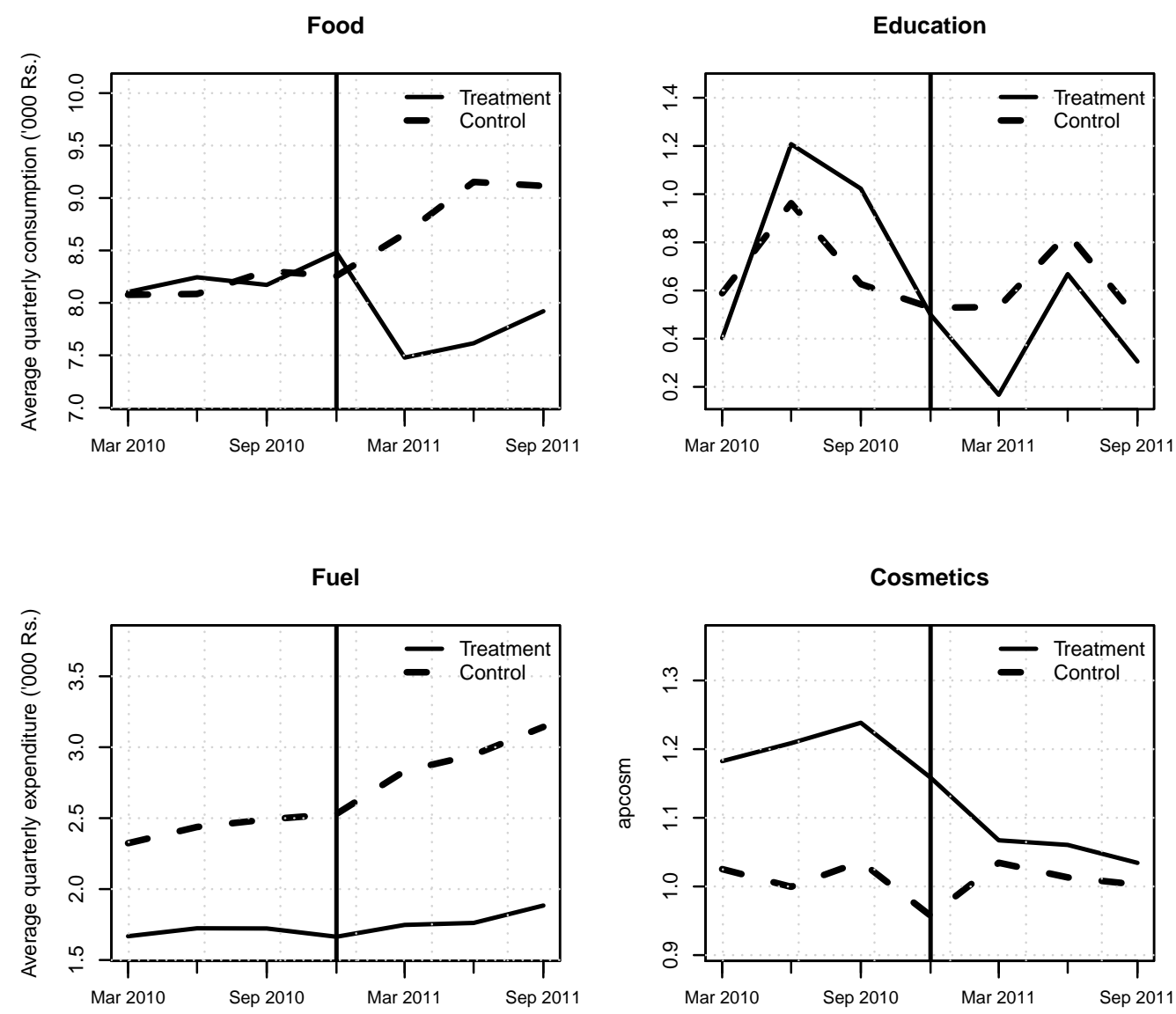
Table 8 DID estimates for average household consumption across treatment and control HRs

The table presents $\beta_{3}$ from the following DID estimation:

$$
C_{i, t}=\beta_{0}+\beta_{1} \mathrm{AP}_{i, t}+\beta_{2} \mathrm{POST}_{-\mathrm{CRISIS}_{i, t}}+\beta_{3}\left(\mathrm{AP}_{i, t} \times \operatorname{POST}_{-\mathrm{CRISIS}_{i, t}}\right)+\epsilon_{i, t}
$$

- $C_{i, t}$ is the average household consumption

- AP takes value " 1 " for an AP HR and "0" for a control HR

- POST-CRISIS = "0" for a period before the micro-finance ban and "1" for a period after.

PRE-CRISIS quarters include the four quarters of March, June, September and December 2010.

Post-CRIsIs includes the four quarters of March, June, September and December 2011.

The table also reports heteroskedasticity-consistent standard errors (std.err.), p-values (p.val), the adjusted p-values (adj.p) and $Q_{\text {power }}$ which is the effect size for different consumption components that could be detected with 70 percent probability.

\begin{tabular}{lrrrrr} 
& \multicolumn{1}{c}{$\hat{\beta}_{3}$} & std.err. & p.val & Adj.p & $Q_{\text {power }}$ \\
\hline Total & $\mathbf{- 3 3 7 5 . 1}$ & $\mathbf{1 4 5 0 . 5}$ & $\mathbf{0 . 0 2}$ & $\mathbf{0 . 0 5} \mathbf{5}^{* *}$ & 6000 \\
Food & -1302.6 & 419.1 & 0.00 & $0.01^{* * *}$ & 2000 \\
Fuel & -504.8 & 199.3 & 0.01 & $0.05^{* *}$ & 1000 \\
Education & -350.3 & 151.8 & 0.02 & $0.05^{* *}$ & 500 \\
Cosmetics & -165.1 & 68.3 & 0.02 & $0.05^{* *}$ & 300 \\
Miscellaneous & -341.5 & 733.3 & 0.64 & 0.80 & 2000 \\
Communication & 12.3 & 98.3 & 0.90 & 0.91 & 500 \\
Clothing & -431.4 & 126.9 & 0.00 & $0.01^{* * *}$ & 500 \\
Transport & -25.9 & 44.6 & 0.56 & 0.80 & 400 \\
Intoxicants & -222.7 & 49.1 & 0.00 & $0.00^{* * *}$ & 200 \\
Rent & -14.2 & 127.2 & 0.91 & 0.91 & 300 \\
EMIs & 31.5 & 63.9 & 0.62 & 0.80 & 500 \\
Restaurant & -82.3 & 71.1 & 0.25 & 0.46 & 400 \\
Health & 17.8 & 58.6 & 0.76 & 0.88 & 200 \\
Recreation & -24.6 & 24.7 & 0.32 & 0.53 & 100 \\
\hline *** indicates $1 \%$ and & $* *$ indicates $5 \%$ & & &
\end{tabular}


significance. This implies an adverse impact on household consumption in the AP HRs of 19.5 percent due to the micro-finance ban, which is consistent with the 19 percent drop calculated from Figure 3 . There is also a drop in the expenditure on different consumption components. For example, there is a drop of 15.8 percent in food and 44.7 percent in education, both of which are statistically significant at the 1 percent and the 5 percent level of significance respectively. ${ }^{15}$

Put together, the above evidence from the quarterly trends on consumption expenditure in the AP and the control HRs, as well as the DID estimation, leads us to conclude that there has been a significant adverse impact on the household consumption caused by the micro-finance ban implemented by the AP State Government.

\subsection{Did volatility of consumption rise with lower ac- cess to micro-finance?}

Since access to finance is important for consumption smoothing, the withdrawal of such access could impact not just on the level of consumption expenditure but also the volatility of consumption. Thus, while we expect a fall in the average household consumption of the treated HRs in AP after the ban, we would expect a rise in the volatility of this average consumption, compared to before the ban was imposed. With the control HRs, we would not expect to see any change in the volatility of consumption.

Table 9 presents the standard deviation of the percentage change in average household expenditure in the period before the ban as $\sigma_{\text {pre-ban }}$ and after the ban as $\sigma_{\text {post-ban. }}$. We first calculate the percentage change in the average expenditure for the $14 \mathrm{HRs}$ in AP and the 14 control HRs as seen in Figure 3.

The table suggests that there been an increase in the volatility of household expenditure between the treatment and control HRs. $\sigma_{\text {post-ban }}$ for overall consumption expenditure is higher for the AP HRs, while it is not significantly higher for the control. There is also some evidence that there has been higher

\footnotetext{
${ }^{15} \mathrm{We}$ also estimate the percentage change drops by conducting a DID of $\log$ (consumption) as well. The results are consistent with our findings using the results in Table 8. For example, we find that total expenditure showed a fall of 18.6 percent, while food showed a fall of 16.2 percent. These results are not presented here but can be made available on request.
} 
Table 9 Volatility of changes in consumption before and after the ban

The table presents the volatility of changes in average household consumption for the AP and the control HRs, in the pre-ban and the post-ban quarters. The component where the volatility of consumption has increased after the ban is food, which at 48.7 percent of total consumption expenditure is the largest component of consumption. While there appears to be a large rise in the volatility of education expenditure after the ban, it is not statistically significant.

\begin{tabular}{lr|rr|rr}
\hline \multirow{2}{*}{ Consumption } & & \multicolumn{2}{|c|}{ Average AP HRs } & \multicolumn{2}{c}{ Average control HRs } \\
\cline { 3 - 6 } & & $\sigma_{\text {pre-ban }}$ & $\sigma_{\text {post-ban }}$ & $\sigma_{\text {pre-ban }}$ & $\sigma_{\text {post-ban }}$ \\
\hline Total & & 2.12 & $8.89^{*}$ & 5.19 & 5.29 \\
Food & 48.7 & 2.30 & $8.98^{*}$ & 1.71 & 3.24 \\
Fuel & 9.6 & 3.37 & 3.04 & 1.73 & 3.74 \\
Cosmetics & 7.1 & 5.19 & 3.94 & 5.75 & 5.40 \\
Education & 5.5 & 93.01 & 135.07 & 47.50 & 50.24 \\
\hline
\end{tabular}

* indicates $\sigma_{\text {post-ban }}$ is higher at 94 percent level of significance.

volatility of consumption expenditure on food and education for the AP HRs after the ban 16

\subsection{Which households were more affected?}

Section 3 proposed that the impact of the micro-finance ban could vary by liquidity constraints. The CP database offers two possible factors based on which to differentiate households with high and low liquidity constraints: (a) income, and (b) location in rural HRs compared to urban HRs. We expect that the households with high liquidity constraints (low income and/or located in rural areas) will suffer a higher impact as a consequence of the

\footnotetext{
${ }^{16}$ The impact of the ban on volatility of consumption expenditure was analysed using a variety of econometric approaches. A simple comparison of the pre- and post-ban periods volatility was compared using the average of the volatility for each of the 14 treatment HRs and their matched controls. Here also, the volatility of total consumption expenditure and the expenditure on food showed an increase, though at a 90 percent level of significance. Next, the impact of the ban was also analysed using the DID framework. The estimated coefficient on the interaction term between AP dummy and the post-crisis dummy was consistently positive across all these approaches showing an increase in the volatility after the ban. However, there was less consistency in the significance of the impact. Food volatility was significantly higher increase at 99 percent in a simple OLS, while education volatility was significantly higher at 99 percent in a robust regression estimation. The details of these alternative estimations can be made available on request.
} 
Table 10 DID estimates on average consumption of high and low income households

This table presents the $\hat{\beta}_{3}$ DID estimators from:

$$
C_{i, t}=\beta_{0}+\beta_{1} \mathrm{AP}_{i, t}+\beta_{2} \operatorname{POST}_{-C_{\text {RISIS }}, t}+\beta_{3}\left(\mathrm{AP}_{i, t} \times \operatorname{POST}_{-\mathrm{CRISIS}_{i, t}}\right)+\epsilon_{i, t}
$$

These are estimated separately for high income (I-3) households in treatment and control HRs, and for low income (I-9) households. The table also reports the heteroskedasticity consistent standard errors (std.err.) and the adjusted p-values (adj.p) for multiple inference for total and various components of household expenditure.

\begin{tabular}{lrrl|rrl}
\hline & \multicolumn{3}{c}{ I-3 (High income, low micro-credit) } & \multicolumn{2}{l}{ I-9 (Low income, high micro-credit) } \\
\hline & $\hat{\beta}_{3}$ & std.err. & adj.p & $\hat{\beta}_{3}$ & std.err. & adj.p \\
\hline Total & $\mathbf{- 8 0 2 4 . 6}$ & $\mathbf{3 7 9 3 . 9}$ & $\mathbf{0 . 1 8}$ & $\mathbf{- 1 4 1 7 . 1}$ & $\mathbf{8 4 2 . 4}$ & $\mathbf{0 . 2 6}$ \\
Food & -2111.7 & 930.1 & 0.18 & -747.9 & 274.0 & $0.05^{* *}$ \\
Fuel & -1446.2 & 560.7 & 0.16 & -49.2 & 77.6 & 0.72 \\
Cosmetics & -396.5 & 224.3 & 0.20 & -68.1 & 42.1 & 0.26 \\
Education & -937.4 & 654.9 & 0.33 & -124.9 & 63.9 & 0.20 \\
Misc. & -224.6 & 1414.5 & 0.94 & -111.8 & 591.4 & 0.85 \\
Comm. & 63.2 & 263.3 & 0.94 & 54.7 & 47.3 & 0.41 \\
Clothing & -656.0 & 336.1 & 0.20 & -213.9 & 82.3 & $0.05^{* *}$ \\
Transport & -252.6 & 136.7 & 0.20 & 53.4 & 35.9 & 0.26 \\
\hline
\end{tabular}

$* * *$ indicates $1 \%$ and ${ }^{* *}$ indicates $5 \%$

micro-finance ban compared with low liquidity households (high income, located in urban areas).

In order to test these, DID estimations are carried out on consumption expenditure of the households with high liquidity constraints in the treatment HRs against similar households in the control HRs. The precision of this analysis is likely to be lower than those reported earlier, since the averages are based on a smaller number of households. There are 131 households in the I-3 category and 2179 households in the I-9 category, across all 14 HRs in AP.

I-3 vs. I-9: Table 10 presents the DID estimations for the high income (I-3) households and the low income (I-9) households. Both households see a drop in average expenditure before and after the ban, but neither of these are statistically significant.

We see many negative coefficients for the I-3 households, which may reflect general equilibrium effects. However, none of these are statisti- 


\section{Table 11 DID estimates between rural and urban HRs}

This table presents the estimation results for:

$$
\begin{aligned}
C_{i, t}= & \beta_{0}+\beta_{1} \mathrm{AP}_{i, t}+\beta_{2} \operatorname{POST}_{-\mathrm{CRISIS}_{i, t}}+\beta_{3}\left(\mathrm{AP}_{i, t} \times \operatorname{POST}_{\left.-\mathrm{CRISIS}_{i, t}\right)}\right. \\
& +\beta_{4}\left(\mathrm{AP}_{i, t} \times \operatorname{POST}_{-\mathrm{CRISIS}_{i, t}} \times \mathrm{RURAL}_{i, t}\right)+\epsilon_{i, t}
\end{aligned}
$$

where $\operatorname{RURAL}_{i, t}$ takes the value 1 if the $i^{t h} \mathrm{HR}$ is rural and 0 if it is urban. $\beta_{4}$ is the impact of the ban on rural AP HRs compared to urban HRs. The results include the heteroskedasticity consistent standard errors and the adjusted p-values.

\begin{tabular}{lrrl}
\hline & $\hat{\beta}_{4}$ & std.error & adj.p \\
\hline Total & $\mathbf{- 5 3 4 9 . 4}$ & $\mathbf{1 1 7 5 . 8}$ & $\mathbf{0 . 0 0 * * *}$ \\
Food & -1469.1 & 228.2 & $0.00^{* * *}$ \\
Fuel & -944.7 & 71.6 & $0.00^{* * *}$ \\
Cosmetics & -269.9 & 49.8 & $0.00^{* * *}$ \\
Education & -215.2 & 91.9 & $0.03^{* *}$ \\
Misc. & -531.0 & 934.7 & 0.66 \\
Comm. & -510.5 & 37.7 & $0.00^{* * *}$ \\
Clothing & -242.4 & 85.9 & $0.01^{* * *}$ \\
Transport & -106.1 & 38.1 & $0.01^{* * *}$ \\
\hline *** indicates $1 \% ; * *$ indicates $5 \%$ &
\end{tabular}

cally significant. In contrast, for the I-9 households, we see statistically significant declines for food and clothing consumption.

These results are consistent with the idea that the impact of the microcredit ban was felt more among households who were directly using micro-finance and had few alternative mechanisms for obtaining credit.

Rural vs. urban: In order to test the effect of the ban on households in rural vs. urban regions, we estimate a DID estimation with a slight modification of the model in Section 5.2 as follows:

$$
\begin{aligned}
C_{i, t}= & \beta_{0}+\beta_{1} \mathrm{AP}_{i, t}+\beta_{2} \mathrm{POST}_{-\mathrm{CRISIS}}{ }_{i, t}+\beta_{3}\left(\mathrm{AP}_{i, t} \times \operatorname{POST}_{-\mathrm{CRISIS}_{i, t}}\right) \\
& +\beta_{4}\left(\mathrm{AP}_{i, t} \times \operatorname{POST}_{-\mathrm{CRISIS}}, t, \times \operatorname{RURAL}_{i, t}\right)+\epsilon_{i, t}
\end{aligned}
$$

where $\operatorname{RURAL}_{i, t}$ takes the value 1 if the $i^{\text {th }} \mathrm{HR}$ is rural and 0 if it is urban. Then $\beta_{4}$ captures the effect of the ban on a rural HR in the treatment units compared with a rural HR in the control unit. The estimated results are presented in Table 11.

Expenditure fell in rural AP for total consumption as well as those components of consumption that had not shown a decline in the overall 
regression ${ }^{17}$ This suggests that households with liquidity constraints caused by a lack of a wider access to finance by virtue of being in a rural region suffered more as a consequence of the ban.

The results in Tables 10 and 11 are based on aggregates across households (average values of consumption) rather than individual households. Given the lack of household level data, it is difficult to establish cross-sectional variation in the impact of the credit ban across households, such as households with liquidity constraints compared to those without. What the results do suggest is that households that can access more credit sources are less vulnerable to shocks in their consumption compared to those households with fewer sources of credit access. The shocks to consumption are long-lasting our results show that consumption had not recovered four quarters after the crisis, implying that once access to credit is taken away, it is very difficult for other sources to compensate for it ${ }^{18}$

\section{$7 \quad$ Threats to validity}

In this section we address alternative explanations that might explain the fall in the average consumption of households observed in the AP HRs, rather than the ban. Three alternatives can be offered:

1. Events other than the ban caused the results.

2. The results are sensitive to the matching strategy.

3. The quality of matches is poor because South India, where other states are as indebted as AP, was excluded from the control pool.

\subsection{Did events other than the ban cause the results?}

A possible criticism of the paper is that some event in AP, other than the micro-credit ban, is what caused the drop in consumption in Section 6. For instance, if there was a drought or a flood in AP but not the other states,

\footnotetext{
${ }^{17}$ Detailed estimation results can be made available on request.

${ }^{18}$ We find that the consumption gap continued to be significant between the treatment and control HRs even in the first two quarters of 2012. These results are not reported here but can be made available on request.
} 
Figure 5 Impact of the ban by micro-finance exposure

This figure plots the impact of the ban on household consumption in the AP HR by the micro-finance exposure of that HR. Here, impact is measured as the change in consumption expenditure in the AP HR before and after the ban, and micro-finance exposure of the $\mathrm{HR}$ is measured as the fraction of borrower households in AP that have borrowed from the SHG/MFI category. The graph shows that there is a sharper fall in consumption with higher exposure to micro-finance.

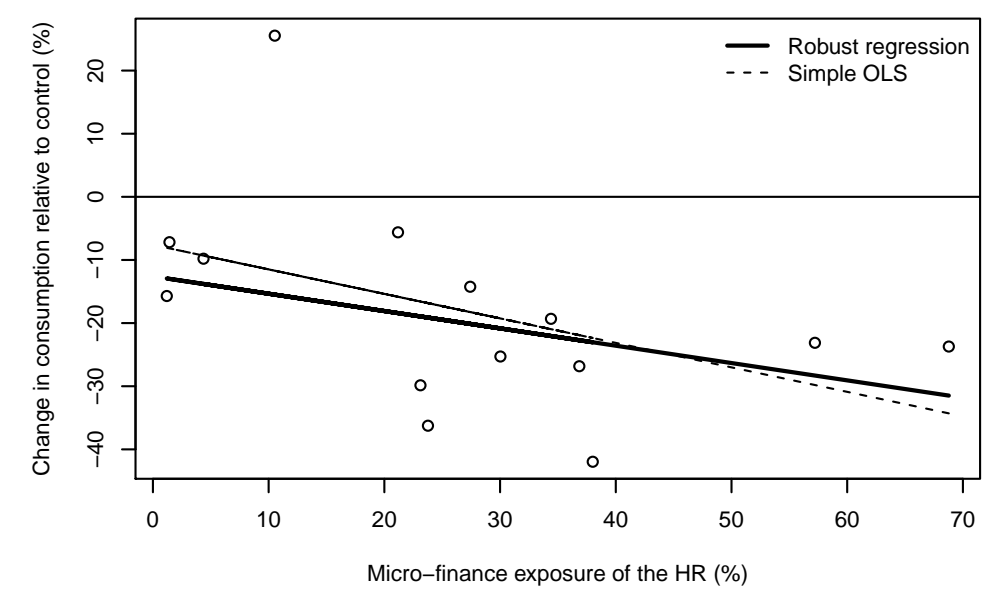

this would adversely effect the average consumption of the AP HRs but not the controls 19

One way to address this concern is to analyse the drop in consumption in a given HR by the exposure of the HR to micro-finance. The exposure to micro-finance is the fraction of borrower households in an HR that have loans from SHG/MFI (Table 3). If a treated HR with a higher micro-finance exposure sees a larger drop in consumption after the ban, the drop can be more confidently attributed to the ban.

Figure 5 presents the change in average household expenditure for the 14 AP HRs by the micro-finance exposure of the HR. Consumption dropped for 13 out of 14 HRs. The decline in consumption is larger on average with higher exposure to micro-finance. We test this statistically by estimating the regression:

$$
\text { Impact }_{i}=\alpha+\beta \times \text { Micro-finance exposure }_{i}+\epsilon_{i}
$$

where we expect $\hat{\beta}$ to be negative and significant if the change is because of

\footnotetext{
${ }^{19}$ There was a drought in AP in the period of July to September 2011. However, this falls after the period analysed in this paper.
} 
the micro-finance ban. A robust regression of the impact of the ban on the consumption of HR $i$ on the micro-finance exposure of $\mathrm{HR} i$ yields $\hat{\beta}=-0.27$ with a t-statistic of -1.98 . This suggests that it was the ban that caused the drop in the consumption in the AP HRs, because other events would not cause such cross-sectional variation in the drop in consumption.

\subsection{Are the results sensitive to the matching strategy?}

We address the concern of the sensitivity of the results to the specific matching algorithm used for the results in Section 6 by estimating the DID using other matching approaches. These include :

1. One by one, dropping each covariate used in the original matching procedure, and testing for the change in results with the new matched HRs.

2. Using a genetic matching algorithm over the same covariates to obtain a set of control HRs.

This is a method of multivariate matching, that uses an evolutionary search algorithm to determine the weight each covariate is given (Diamond and Sekhon, 2012).

3. Using the "proportion of women in an HR" as a match variable as a proxy for exposure to micro-credit, since micro-finance institutions (either SHG or MFI) typically lend to women.

Table 12 shows estimates from these DID estimations. All the estimated coefficients are negative, and all but one are significant. Thus, while different approaches yield coefficients that vary in magnitude, the direction and significance in each case is consistent with those of the estimates presented in Table 8 in Section 6. Thus, we infer that the result of negative impact of the micro-finance ban on household consumption is not sensitive to the particular matching strategy used.

\subsection{Is the match quality poor because South India is excluded?}

Section 5.1 argued that in order to avoid spillover effects, HRs from the states of South India were removed from the control pool. To the extent that a certain partial treatment effect was probably found all over South India, the use of HRs from South India in the control pool would generate a downward 


\begin{tabular}{|c|c|c|c|c|c|}
\hline & & $\hat{\beta}_{3}$ & std.err & p.val & adj.p \\
\hline \multicolumn{6}{|l|}{ Baseline result } \\
\hline & Total & -3375.1 & 1450.5 & 0.02 & $0.05^{* *}$ \\
\hline & Food & -1302.6 & 419.1 & 0.00 & $0.01^{* * *}$ \\
\hline \multicolumn{6}{|c|}{ 1. Dropping one covariate at a time } \\
\hline \multirow[t]{2}{*}{ Average household income } & Total & -4100.30 & 1595.19 & 0.01 & $0.03^{* *}$ \\
\hline & Food & -1476.38 & 468.67 & 0.00 & $0.01^{* *}$ \\
\hline \multirow{2}{*}{ Number of households } & Total & -3750.54 & 1414.87 & 0.01 & $0.03^{* *}$ \\
\hline & Food & -1329.36 & 427.95 & 0.00 & $0.01^{* *}$ \\
\hline \multirow[t]{2}{*}{ Working age population } & Total & -2862.41 & 1340.42 & 0.03 & $0.08^{*}$ \\
\hline & Food & -1117.59 & 387.29 & 0.00 & $0.02 * *$ \\
\hline \multirow[t]{2}{*}{ Graduated $10^{\text {th }}$ grade } & Total & -3993.80 & 1452.54 & 0.01 & $0.02^{* *}$ \\
\hline & Food & -1434.57 & 447.86 & 0.00 & 0.01 \\
\hline \multirow{2}{*}{ Financially excluded } & Total & -2794.62 & 1508.09 & 0.07 & 0.16 \\
\hline & Food & -1189.45 & 432.18 & 0.01 & $0.03^{* *}$ \\
\hline \multirow[t]{2}{*}{ Farmer } & Total & -3556.64 & 1403.00 & 0.01 & $0.03^{* *}$ \\
\hline & Food & -1437.70 & 417.28 & 0.00 & 0.01 \\
\hline \multicolumn{6}{|c|}{ 2. Using a genetic matching algorithm } \\
\hline & Total & -4648.2 & 1834.2 & 0.01 & $0.04^{* *}$ \\
\hline & Food & -1814.9 & 436.3 & 0.00 & $0.00^{* * *}$ \\
\hline \multicolumn{6}{|c|}{ 3. Adding proportion of women } \\
\hline & Total & -3105.20 & 1619.58 & 0.06 & 0.14 \\
\hline & Food & -1196.02 & 504.64 & 0.02 & $0.07^{*}$ \\
\hline
\end{tabular}


Table 13 DID estimates including states bordering AP

This table presents results of a DID estimation from Section 5.2 where the control group includes HRs from the three south Indian states of Tamil Nadu, Kerala and Karnataka which are more similar to AP in indebtedness to AP than the rest of the country.

\begin{tabular}{lrrll} 
& $\hat{\beta}_{3}$ & std.err. & p.val & adj.p \\
\hline Total & $\mathbf{- 3 0 6 9 . 8 2}$ & $\mathbf{1 4 0 9 . 6 6}$ & $\mathbf{0 . 0 3}$ & $\mathbf{0 . 0 8}$ \\
Food & -1240.71 & 435.45 & 0.00 & $0.02^{* * *}$ \\
Fuel & -378.21 & 206.38 & 0.07 & 0.15 \\
Cosmetics & -173.09 & 70.61 & 0.02 & $0.05^{* *}$ \\
Education & -353.98 & 146.71 & 0.02 & $0.05^{* *}$ \\
Misc. & -267.86 & 680.20 & 0.69 & 0.81 \\
Comm. & -13.05 & 93.99 & 0.89 & 0.89 \\
Clothing & -409.77 & 122.83 & 0.00 & $0.01^{* * *}$ \\
Transport & -39.04 & 46.85 & 0.41 & 0.55 \\
\hline
\end{tabular}

*** indicates $1 \%, * *$ indicates $5 \%$ and $*$ indicates $10 \%$

bias in the measured treatment effect. However, this design decision has an adverse impact upon the quality of matching as the presence of micro-finance in other parts of the country was more limited.

In order to assess the impact of this design decision, we redo the matching exercise without excluding South India from the control pool. Table 13 presents these modified results. These also show a decline in consumption in AP after the ban, which is statistically significant.

\section{Conclusion}

In recent decades, there has been a rapid growth in the micro-credit business by financial firms utilising business models such as the joint-liability structure to lend to low-income households. The higher levels of credit access ought to have been an unambigiously superior outcome. In reality however, these developments have been marred by concerns about consumer protection. Policy makers have grappled with these questions worldwide, and have often implemented a variety of interventions, ranging from relatively subtle rules on consumer protection to restrictions. The role for new kinds of microcredit firms, and the optimal public policy response to these, has relevance worldwide.

The existing research evidence on these questions is drawn from three strate- 
gies: randomised trials, general equilibrium models and natural experiments. Randomised trials are inevitably limited by the magnitude of research budgets, general equilibrium models do not examine all channels through which credit can matter, and the existing papers which utilise natural experiments are often forced to use proxies for consumption.

The contribution of this paper lies in utilising a large natural experiment - a complete ban on micro-finance in the Indian state of Andhra Pradesh (AP) that has the population of Germany - and in having high quality measurement of consumption through a panel dataset of 150,000 households observed every quarter all over the country. The ban was imposed in only one state, giving us controls from other locations in the country.

The results suggest a fairly large negative impact of the ban on micro-finance. In AP, consumption dropped by 19.5 percent over the first four quarters after the micro-finance ban. The impact of the ban is visible across all income classes - including those which use little micro-credit themselves - which suggests general equilibrium effects. While the ban on micro-finance was initiated by policy makers in AP under the claim that this would help poor people, it has hurt everyone.

There are intriguing analogies between the experiment in AP - where a subset of society that was using micro-finance abruptly lost credit access and the macroeconomics and finance literature on deleveraging (Eggertsson and Krugman, 2012). The develeraging literature focusses on what happens when some borrowers in a country are highly indebted and face an abrupt shock to credit access. The difficulties faced by these borrowers impacts the economy at large, and the consequences are not restricted to just the set of borrowers. The natural experiment that we have examined in AP appears to have some similar characteristics. Only a subset of the population was borrowing from micro-finance institutions, but when an abrupt loss of microcredit access took place, it generated negative consequences across all income classes in AP. There was an adverse impact upon welfare through reduced consumption and through enhanced consumption volatility.

A drawback of the analysis is that we only observe household aggregates at the level of geographical areas and income classes, rather than individual households. Record level data might reveal that welfare is improved without micro-finance, for certain households. For example, we know that for the income class with the highest use of micro-credit, there was a negative impact on food consumption, while for households in the income class with the lowest use of micro-credit, there was no significant impact. Since we lack household level records, we cannot distinguish between a bigger impact on 
the households that directly used micro finance, and indirect effects on their peers in the same income class. When such data is eventually released, these effects could be measured.

The findings in this paper suggest that the overall average treatment effect associated with banning micro-finance in Andhra Pradesh was negative. One lesson is that a blunt policy instrument, such as a complete ban of microfinance, is inadvisable. In the global debate about the welfare consequences of for-profit micro finance, this would suggest that extreme government restrictions are ill-advised. Thus, even though this analysis does not rule out the potential presence of market failure in the form of weak decision making by some poor people, the optimal response to market failures involves a more subtle approach of consumer protection, rather than the blunt instrument of a ban. These questions are important avenues for future research. 


\section{References}

Armendáriz, Beatrice, and James Morduch (2010): The economics of microfinance. Cambridge, MA.: MIT Press, second edn.

Arunachalam, Ramesh S. (2010): "The 2010 Andhra Pradesh MicroFinance Crisis Revisited...," Blog: "Candid Unheard Voice of Indian Micro-finance", http://microfinance-in-india.blogspot.com/2010/12/2010andhra-pradesh-micro-finance.html.

Augsburg et. al. (2012): "Microfinance, poverty and education," Working Papers 18538, NBER.

Ballem et.al. (2011): "What are Clients doing Post the Andhra Pradesh MFI Crisis?," Discussion paper, MicroSave.

Banerjee, Abhijit V., Esther Duflo, Rachel Glennerster, and Cynthia Kinnan (2013): "The Miracle of Microfinance? Evidence from a randomized evaluation," Working Paper 13-09, MIT Department of Economics.

Blundell, Richard, and Monica Costa Dias (2000): "Evaluation methods for non-experimental data," Fiscal Studies, 21(4), 427-468.

Buera, Francisco J., Joseph P. Kaboski, and Yongseok Shin (2012): "The Macroeconomics of Microfinance," Working Paper 17905, NBER.

Crépon, Bruno, Florencia Devoto, Esther Duflo, and William Parienté (2011): "Impact of microcredit in rural areas of Morocco: Evidence from a Randomized Evaluation," .

Datta, Sankar, and Vijay Mahajan (2003): "Savings and Credit Movement of Andhra Pradesh," Discussion paper, BASIX.

Diamond, Alexis, and Jasjeet S. Sekhon (2012): "Genetic Matching for Estimating Causal Effects: A General Multivariate Matching Method for Achieving Balance in Observational Studies," Review of Economics and Statistics, (forthcoming).

Eggertsson, Gauti B., and Paul Krugman (2012): "Debt, Deleveraging and the Liquidity Trap: A Fisher-Minsky-Koo Approach," Quarterly Journal of Economics, 127(3), 1469-1513.

Kaboski, Joseph P., and Robert M. Townsend (2011): "A Structural Evaluation of a Large-Scale Quasi-Experimental Microfinance Initiative," Econometrica, 79(5), 1357-1406. 
- (2012): "The Impacts of Credit on Village Economies," American Economic Journal: Applied Economics, 4(2), 98-133.

Karlan, Dean, and Jonathan Zinman (2010): "Expanding Credit Access: Using Randomized Supply Decisions to Estimate the Impacts," Review of Financial Studies, 23(1), 433-464.

(2011): "Microcredit in Theory and Practice: Using Randomized Credit Scoring for Impact Evaluation," Science, 332, 1278-1284.

Leth-Petersen, Soren (2010): "Intertemporal consumption and Credit Constraints: Does Total Expenditure Respond to an Exogenous Shock to Credit?," The American Economic Review, 100(3), 1080-1103.

Lusardi, Annamaria, and Peter Tufano (2009): "Debt Literacy, Financial Experiences, and Overindebtedness," Working Paper 2009-08, CFS, http://hdl.handle.net/10419/43242.

Melzer, Brian T. (2011): "The real costs of credit access: Evidence from the payday lending market," The Quarterly Journal of Economics, 126, $517-555$.

MFIN (2012): "The MicroScape," Discussion paper, Microfinance Institutions Network.

Morgan, Donald P., and Michael Strain (2008): "Payday Holiday: How Households Fare After Payday Credit Bans," Staff Report 309, Federal Reserve Bank of New York.

Morse, Adair (2011): "Payday lenders: Heroes or villains?," Journal of Financial Economics, 102(1), 28-44.

Rosenbaum, Paul R., and Donald R. Rubin (1983): "The central role of the propensity score in observational studies for causal effects," Biometrika, $70,41-55$.

(1985): "Constructing a control group using a multivariate matched sampling method that incorporates The Propensity Score.," American Statistician, 39, 33-38.

Rosenzweig, Mark R. (2001): "Savings Behaviour in Low-Income Countries," Oxford Review of Economic Policy, 17(1), 40-54.

Sa-dhan (2007): "Core Values and Voluntary Mutual Code of Conduct For Microfinance Institutions," Discussion paper, Sa-Dhan : The Association of Community Development Finance Institutions. 
Sane, Renuka, and Susan Thomas (2013): "Regulating microfinance institutions," Economic and Political Weekly, 68(5).

Shylendra, H. S. (2006): "Microfinance Institutions in Andhra Pradesh," Economic and Political Weekly, pp. 1959-1963.

Skiba, Paige Marta, and Jeremy Tobacman (2009): "Do payday loans cause bankruptcy?," Research Paper 11-13, Vanderbilt Law and Economics.

Smith, Jeffrey A., and Petra E. Todd (2005): "Does matching overcome LaLonde's critque of nonexperimental estimators," Journal of Econometrics, 125, 305-353.

Srinivasan, N. (2010): "Microfinance: State of the Sector Report 2010," Discussion paper, Access Development Services, Sage Publications.

(2012): "Microfinance India: State of the Sector Report 2011," Discussion paper, Access Development Services, Sage Publications.

State government of Andhra Pradesh (2010): "An Ordinance to protect the women Self Help Groups from exploitation by the Micro Finance Institutions in the State of Andhra Pradesh and for the matters connected therewith or incidental thereto," State government of Andhra Pradesh.

Stuart, Elizabeth A. (2010): "Matching methods for causal inference: A review and a look," Stat Sci, 25(1), 1-21.

Thaler, Richard H. (1990): "Anomalies: Saving, Fungibility, and Mental Accounts," The Journal of Economic Perspectives, 4(1), 193-205.

Zinman, Jonathan (2010): "Restricting consumer credit access: Household survey evidence on effects around the Oregon rate cap," Journal of Banking and Finance, 34(3), 546556. 